\title{
ESTIMATION OF HEAT FLUX CAUSED BY SOLAR IRRADIATION ON A DRIVER OF PASSENGER CAR USING NUMERICAL SIMULATION
}

\author{
Dragan Ružić* \\ Faculty of Technical Sciences, Novi Sad, Serbia \\ Borivoj Stepanov \\ Faculty of Technical Sciences, Novi Sad, Serbia
}

In this paper, the influence of solar radiation direction and intensity on thermal flux on passenger vehicle driver's body was analysed. The analysis was carried out on a virtual model of a vehicle cabin. The results showed that the highest heat flux caused by solar radiation could occur when the sun is shining in the front of the vehicle, as proposed in standard ISO 14505-2: 2008. Under these conditions, driver's chest is the segment with the highest heat flux. The unfavourable situation due to highly asymmetric thermal condition is also when the sun is shining on the left side of the cabin. From that reason, paying attention to solar characteristics of glass and to design of air distribution system in such way that air-conditioner vents can be directed to areas with the highest fluxes is an efficient way to reduce the driver's and passenger's thermal stress.

Key words: Cabin, Solar radiation, Virtual thermal manikin, Automotive glass, Thermal comfort

\section{INTRODUCTION}

Thermal conditions in a vehicle cabin are more adverse in hot than in cold ambient. Higher ambient temperatures, accompanied with solar radiation, cause increase of both interior air and surface temperatures above safety limits. From that reason, even under moderate outside conditions the closed cabin act like green house and its closed interior could become unpleasant, unbearable and even dangerous for the occupants [03]. Vehicle cab ergonomics is a key factor in ensuring driver's optimum working performance, which could easily become the weakest link in the process of vehicle driving. Consequences of poor ergonomics of driver's workplace could be the decrease of the traffic safety level [02].

Experimental determination of local heat fluxes on human body surface caused by solar radiation demands the use of complex and expensive measurement equipment and test facilities. The other way is to simulate these processes in virtual experiments, as in other fields of research (e.g. virtual reality in vehicle development, simulation of dynamic mechanical processes etc.) $[04,09,10,17]$. This paper deals with numerical modelling of effects of the solar radiation transmitted through a vehicle cabin glazing.
Many researches are focused on human body exposure to solar radiation, and this problem is especially interesting in the context of motor vehicles. In the comprehensive project focused on the reduction of vehicle auxiliary load, done by National Renewable Energy Laboratory [12], variety of researching methods were used to investigate and develop innovative techniques and technologies for lowering thermal loads. The aim of the research was to investigate solutions for improvement of fuel economy of air-conditioning system. They concluded that reflecting the solar radiation incident on the vehicle's glass is the most important factor in making significant reductions in the thermal loads. The use of solarreflective glass can reduce the average air temperature and the seat temperature. Application of reflective shades and electrochromic switchable glazing is also effective techniques for reducing the solar energy entering the passenger compartment.

The project presented in the project report by Bohm et al. [01], concerns the thermal effect of glazing in cabs with large glass areas. The effect of different kind of glass and design of the windows as well as the effects of sun protection and insulation glazing have been studied 
and evaluated, using the thermal manikin called AIMAN. Results showed that neither in severe winter conditions, nor in sunny summer conditions, could acceptable climate be obtained with standard glazing in cabs with large glass areas.

Han and Huang [05] performed CFD simulations where the effects of solar radiation were considered in a virtual model of actual vehicle. They used the comfort model that has the ability to predict the local thermal comfort level of an occupant in a highly non-uniform thermal environment, taking into account direct solar flux on each passenger too. Results of investigation of different types of glazing and solar intensities showed importance of the solar radiation on thermal sensation, which can cause highly asymmetric thermal condition.

Results of Ružić et al. [14, 15, 16] showed that cabin glazing is the most influencing factor in cabin heat gain. They concluded that the highest heat flux that enters the cabin is caused by solar radiation through the glass, which could be several times higher than the heat transferred by other modes. Therefore, the selection of appropriate glass properties could be the way to reduce heat load on driver. Furthermore, the heat load on the driver is highly dependent from the shape of a cabin and glass solar properties.

Lee et al. [08] carried out numerical simulation in order to investigate the influence of spectral effect on airflows and temperature distribution in the passenger car cabin. For the purpose of the investigation, the experimental measurement of glass spectral properties was performed. They concluded that the solar load in the cabin depends on the glass properties and the solar spectrum. The direct effects of the solar radiation on passengers were not considered in the research.

The aim of the paper is to investigate effects of the sun position relative to the vehicle cabin on heat fluxes caused by solar radiation over the driver's body surface. Although the vehicle changes its relative position to the sun, these situations could be of interest when the vehicle is stationary, slow moving in traffic jam, or during the prolonged driving on straight motorways. In addition, the goal is to identify the worst case regarding the heat gain caused by solar radiation, in order to reduce the risk of thermal discomfort.

\section{METHOD}

Estimation of heat fluxes caused by solar radiation was done using the numerical simulations. The simulations were carried out in STAR CCM+ software.

The CAD model of the virtual thermal manikin (VTM) is a simplified humanoid in the sitting posture. The manikin's body is symmetric, with its posture defined by characteristic points in places where the main body joints are (hips, shoulders, neck, elbows etc). Main body dimensions are adopted from CATIA database for a 50th percentile European male, and the body is divided into 18 segments (Figure 1, left). According to the chosen sizes of the body, the VTM is $1.74 \mathrm{~m}$ tall and weighs $68 \mathrm{~kg}$. The area of VTM body surface in sitting position is $1.796 \mathrm{~m}^{2}$. The VTM surface is discretized in around 13,600 surface elements [13] (Figure 1, right).

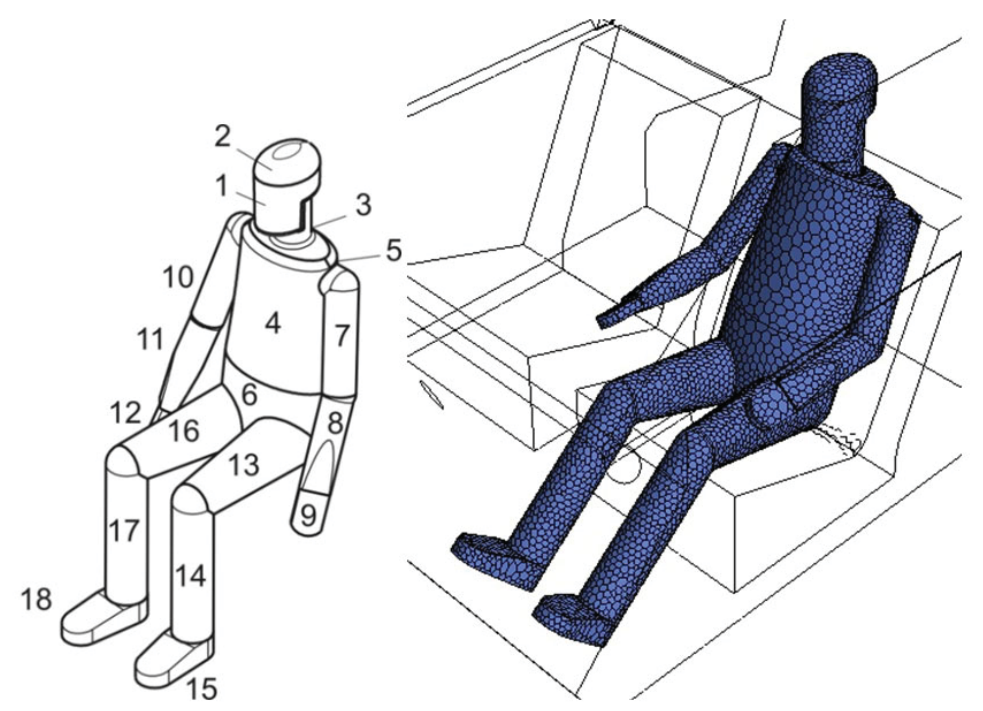

Figure 1: Left - Virtual thermal manikin with numbered segments. Right - The VTM surface mesh 
The cabin interior was modelled after the shape and dimensions of mid-sized passenger hatchback car, with significant simplification of the cabin geometry.

The problem was treated as a steady-state threedimensional, with stationary bodies and boundaries. Solar load was calculated using Solar load model incorporated in CFD software STAR$\mathrm{CCM}+$. Although the primary purpose of the CFD software is simulation of thermal and flow processes, this software can be used for modelling of the radiation processes as well [21].

The amount of the solar radiation energy that will be absorbed by the body will depend on the effective projected area and on the solar absorptivity of the body surface. Solar absorptivity of the hu $\urcorner$ man skin is around 0.62, while solar absorptivity for clothing depends on the colour [07, 11]. In this research, solar absorptivity of all VTM's segments was set to 0.62 .
The coordinate system for the orientation of the direct solar flux is shown in the Figure 2. In this study, the gray spectrum model is used and the total solar loads represent the full-thermal spectrum, divided in direct and diffuse radiation. Based on the results given in [08], when the spectral solar radiation and optical properties of the materials are considered, the heat fluxes would be in some extent higher than in the cases without considering spectral effect. For comparative purposes regarding the sun positions, the gray spectrum model is chosen as compromise between the accuracy and computational time.

The solar load model is defined by the sun direction and solar flux intensity. The sun direction vector in a specified coordinate system is described by azimuth and altitude angles. The solar flux is consisted of the direct and the diffuse solar fluxes [21].

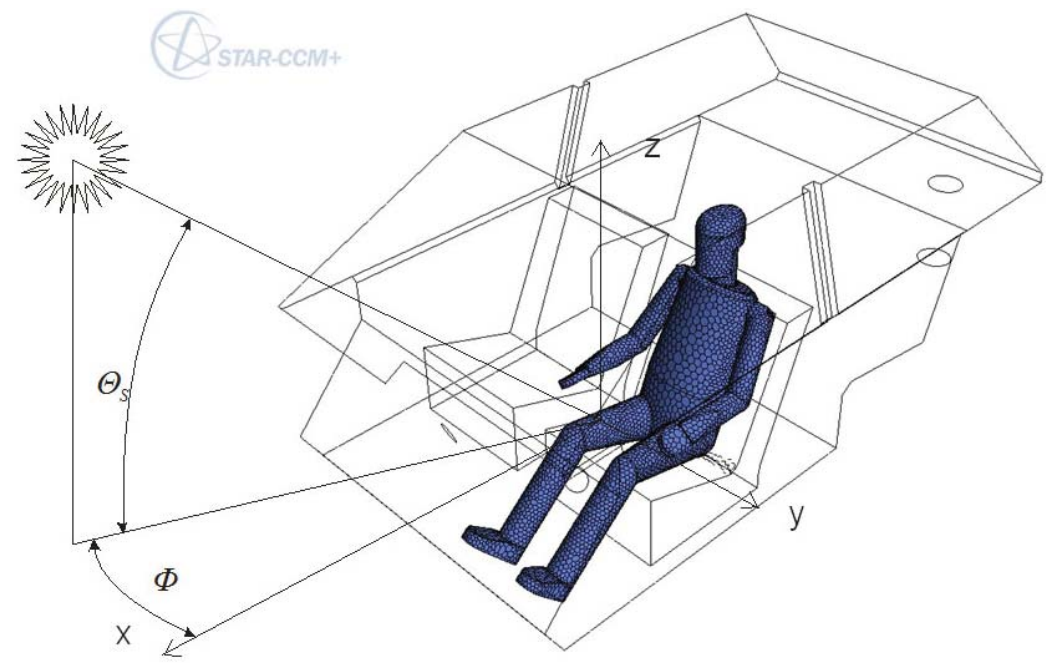

Figure 2: Orientation of the cabin in solar coordinate system: $\theta_{s}-$ solar altitude (sun elevation), $\Phi$ - azimuth angle

Solar irradiation is variable depending on the position of the sun as well as the orientation of the cabin. The sun position varies throughout the day and year due to the earth's rotation on its own axis and its orbit around the sun. Graph in Figure 3 presents the values of maximum ("clear sky") intensity of normal irradiation and its variations during the daylight, in a central European region [18].

Vehicle cabin glazing is semi-transparent medium where solar irradiation can be partially reflected, absorbed and transmitted, Figure 4. While the transmitted radiation influences how much shortwave radiation reaches the body, the absorbed part of the solar energy influences the temperature of the glass. The increase of glass temperature causes heat transfer to the cab interior by both convection and longwave radiation $[06,14,15]$. Consequently, the solar radiation causes discomfort by increasing the interior air and surface temperatures. In this research, only transmitted solar radiation that falls directly on the driver's body was analyzed, since it causes discomfort due to significant heat gain and radiation asymmetry.

Glass performance regarding the impact of solar radiation is determined by the optical properties of the glass. Using available values of glass properties for green tinted automotive glass with $75 \%$ transmittance of visible light, the normal 
solar transmissivity was set to $0.5[08,20]$. The maximum solar transmissivity of the glass is in region of incident angles less than $40^{\circ}$, but de- creasing of the transmissivity with the increase of the incident angle was not taken into account in this research.

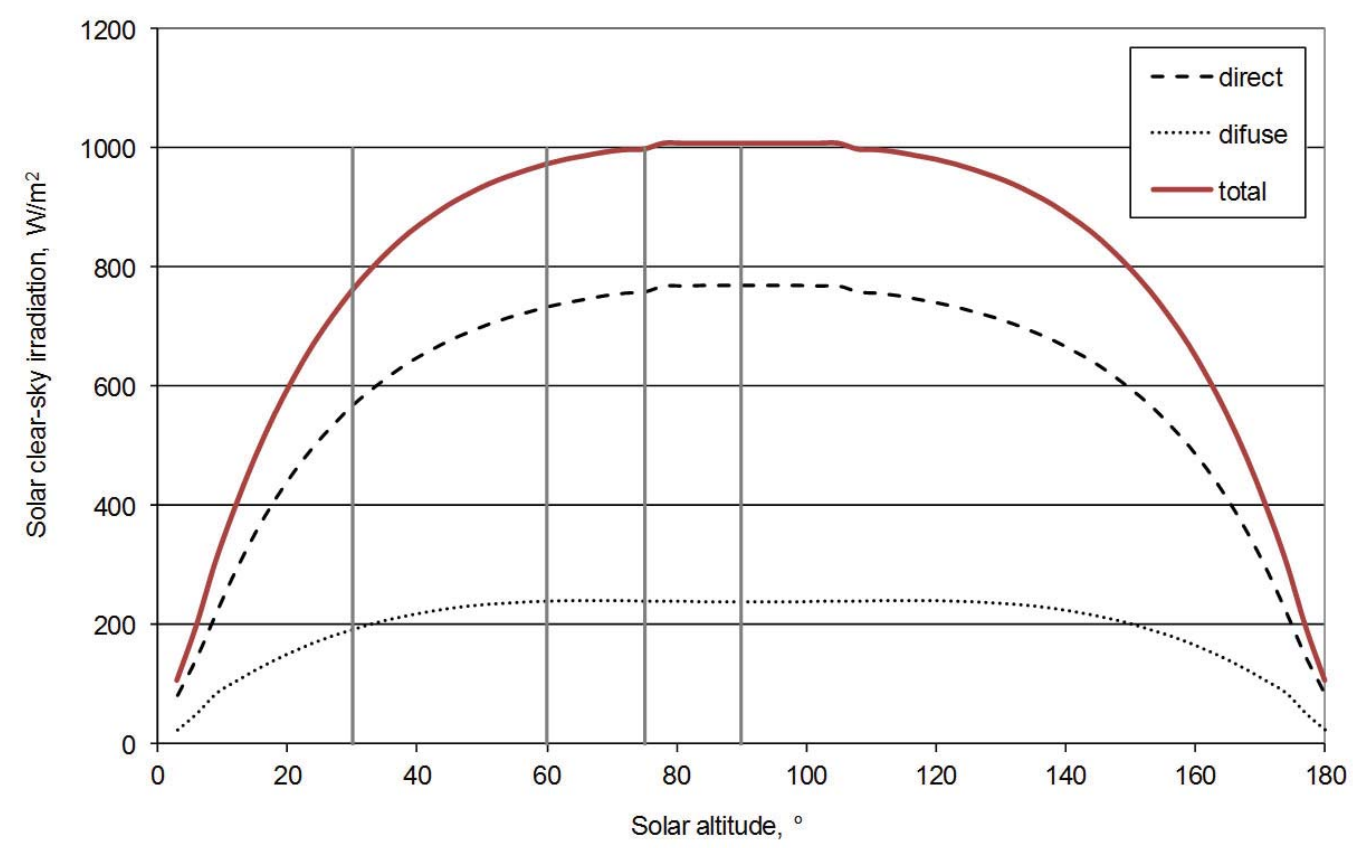

Figure 3: Solar clear-sky irradiation in a central European region on a day in July [18]. Vertical lines present the solar altitudes that were considered in the analysis

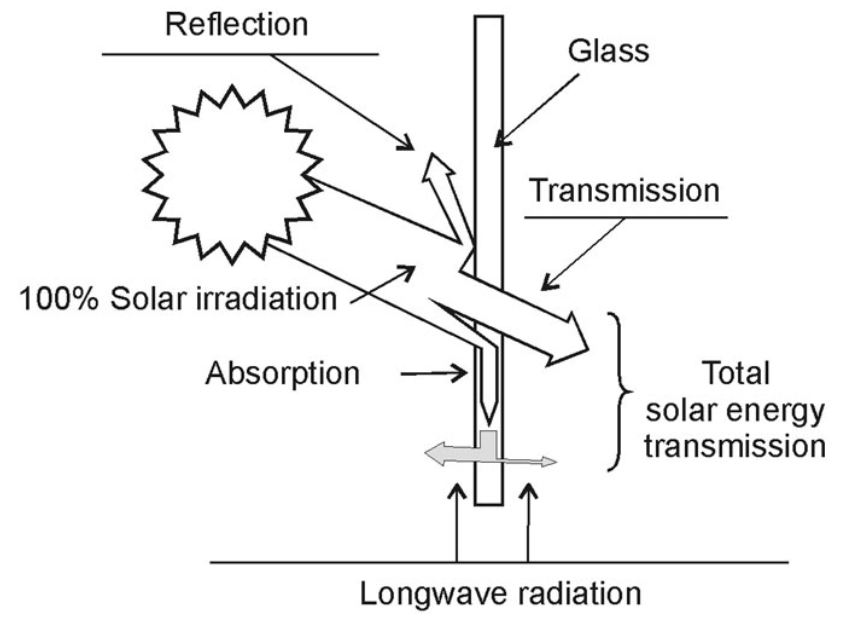

Figure 4: Solar energy transmission through the glass

The heat flux on a driver's body segment caused by the solar radiation is calculated according to [07]:

$q_{S}=G_{S} \cdot \tau_{S} \cdot \alpha_{S}, \mathrm{~W} / \mathrm{m}^{2}$

This mode of heat transfer is independent of other boundary conditions parameters, like ambient temperature, air velocity or radiant temperature (i.e. Iongwave radiation). The direct solar irradiation on the virtual manikin surface $\left(G_{S} \bullet_{S}\right)$ was directly obtained by CFD simulation post-processing.

\section{VIRTUAL EXPERIMENTS, RESULTS AND DISCUSSION}

The aim of the research was to investigate influence of the sun position relative to the vehicle cabin on driver's body heat fluxes caused by solar radiation. The results should indicate the worst case regarding the local heat flux intensity and the radiation asymmetry. Consequently, the areas on the driver's body that must be cooled by the forced airflow were pointed out.

Simulation were performed for four different sun altitudes $\left(\theta_{S}=30^{\circ}, 60^{\circ}, 75^{\circ}\right.$ and $\left.90^{\circ}\right)$ and five 
azimuth angles $\left(=0^{\circ}, \pm 45^{\circ}\right.$ and $\left.\pm 90^{\circ}\right)$. The values of direct and diffuse solar irradiation were changed with the sun altitude, according to the Figure 3. The conditions include solar irradiation intensity defined by standard ISO 14505-2: 2008 for determination of thermal conditions in vehicle cabin during the cool-down regime: solar irradiation of $800 \mathrm{~W} / \mathrm{m}^{2}$, at altitude of $60^{\circ}$ and azimuth of $0^{\circ}$ [19].

Values of the heat flux for the whole body in dependence of solar azimuth and altitudes are shown on Figure 5. According to the trend of the whole body heat flux in dependence of azimuth, the highest value could be expected at azimuth angle of around $-15^{\circ}$ with solar altitude of $60^{\circ}$. This condition is very close to the conditions defined by the standard ISO 14505-2: 2008.
The largest effective projected radiation area $A_{\text {eff }}$ of unprotected sitting person is with azimuth and altitude angles of $30^{\circ}$ and $15^{\circ}$ respectively, giving the total surface equal to [11]:

$$
A_{\text {eff }}=A_{D u} \cdot 0.72 \cdot 0.33=0.238 A_{D u}, \mathrm{~m}^{2}
$$

The total surface of human body ADu can be calculated from body weight and height (after Dubois [11]). The factor 0.72 in the equation (2) is effective radiation area factor, and the factor 0.33 is projected area factor [11]. However, due to position of opaque cabin surfaces and lower intensity of the solar irradiation when the sun is very low in the sky, this case is not critical in passenger vehicle. Distribution of the heat flux on VTM's surface is visualized on Figure 6 and the values are given on Figure 7.

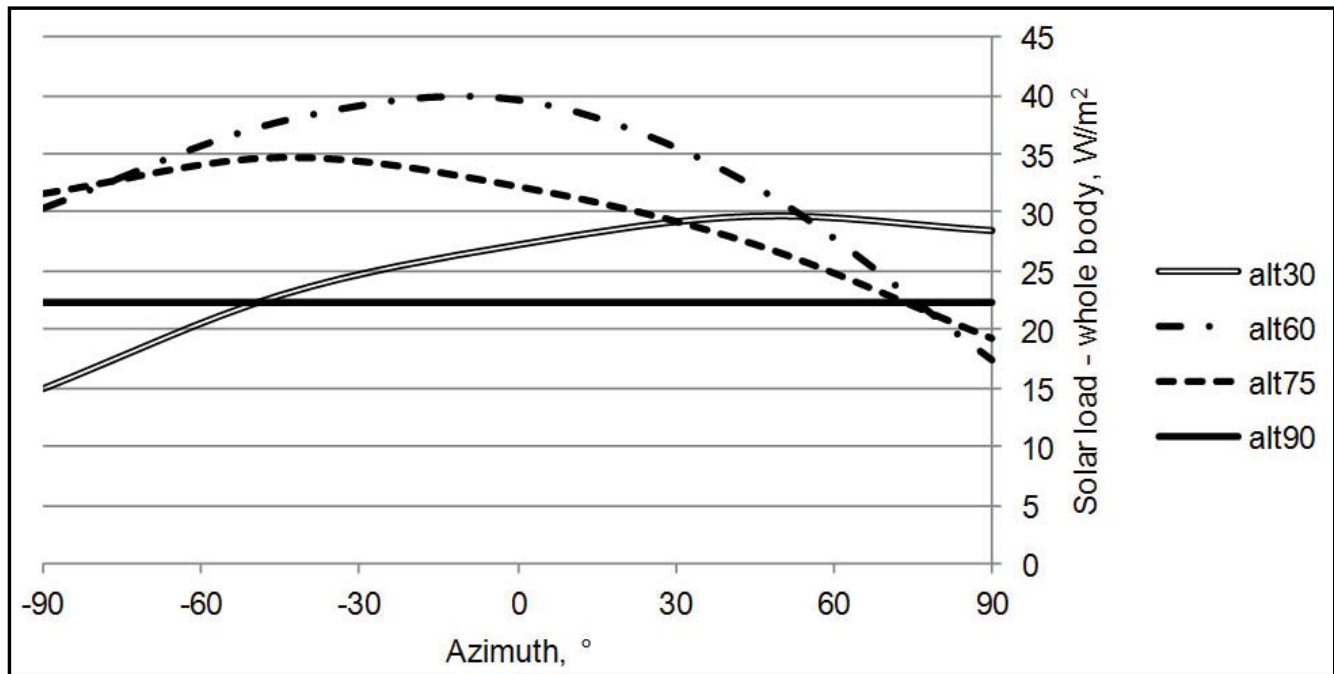

Figure 5: Values of the heat flux for the whole body in dependence of solar azimuth and altitude angles

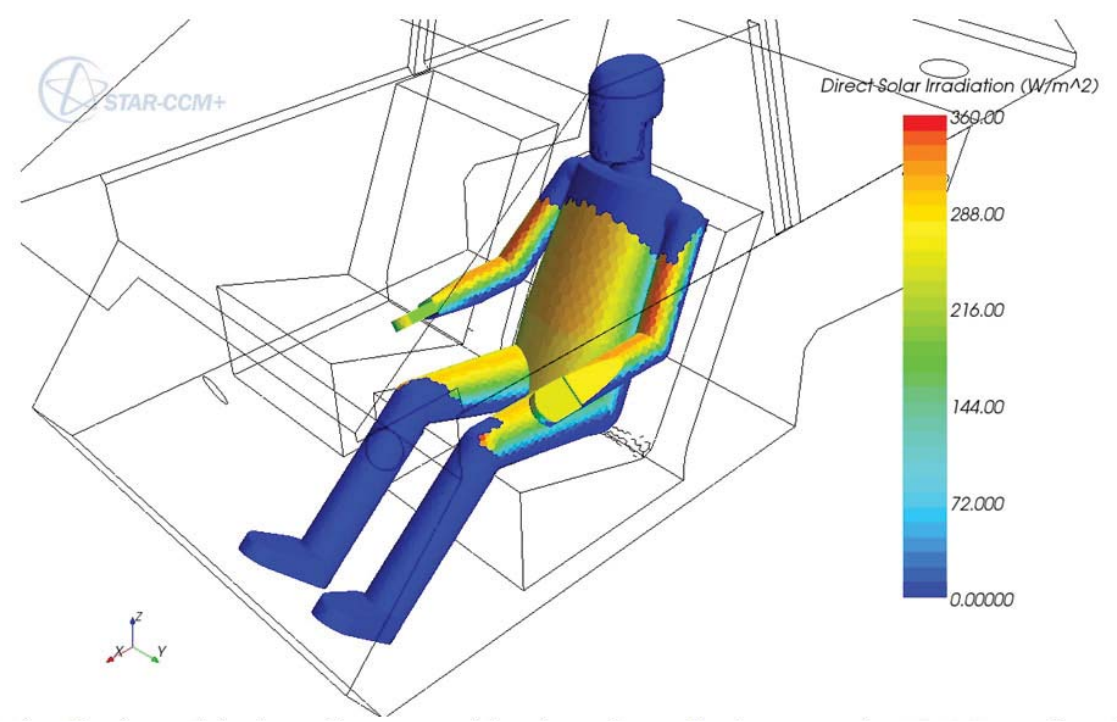

Figure 6: Distribution of the heat flux caused by the solar radiation over the VTM's surface in the case with the highest heat flux for the whole body 


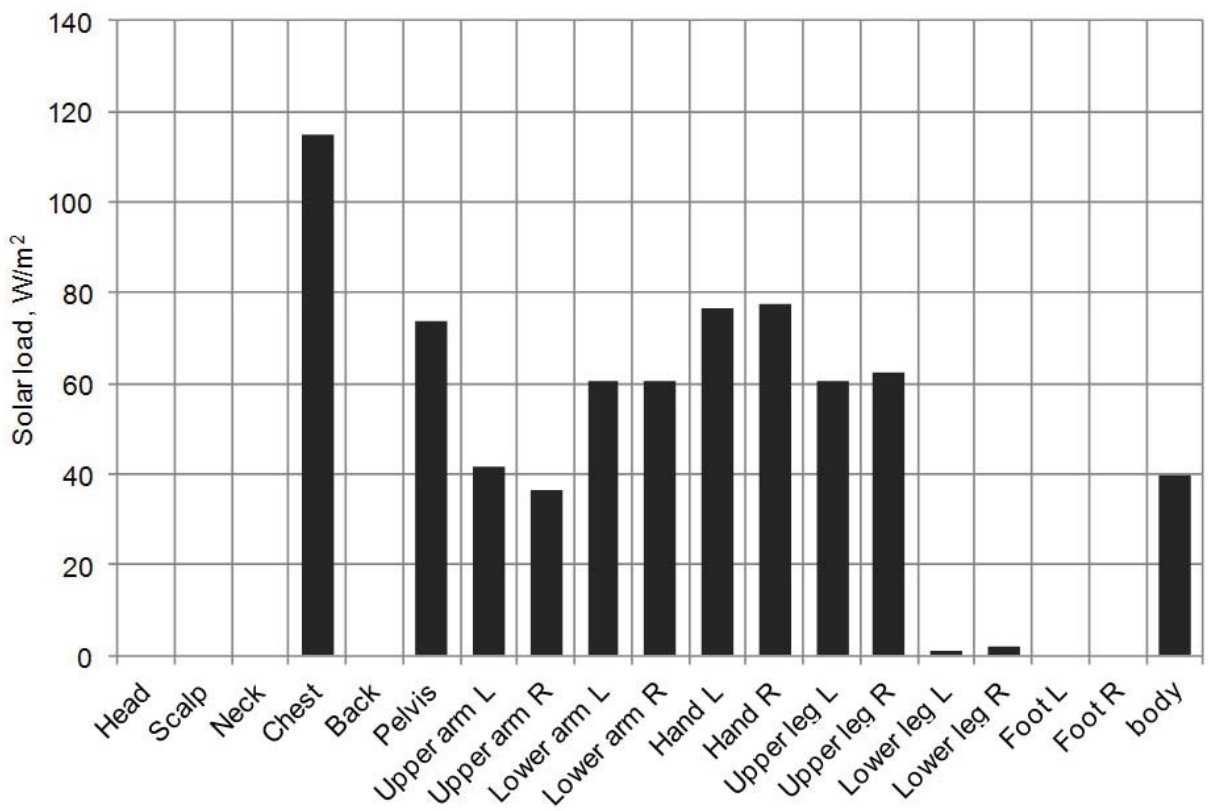

Figure 7: Values of the heat flux caused by the solar radiation on VTM's segments in the case with the highest heat flux for the whole body

The segment with the highest local value of heat flux was the driver's chest, at solar azimuth $0^{\circ}$, when the sun was lower in the sky, i.e. at altitude $30^{\circ}$, Figure 7 . When the sun is high in the sky (around the noon), the driver's head is protected relatively good by the cabin roof and the upper part of the body is exposed to the transmitted solar radiation only when the sun is low in the sky, at altitude below $15^{\circ}$. However, under this circumstance solar irradiation is ap pproximately at one-half of its maximum value.

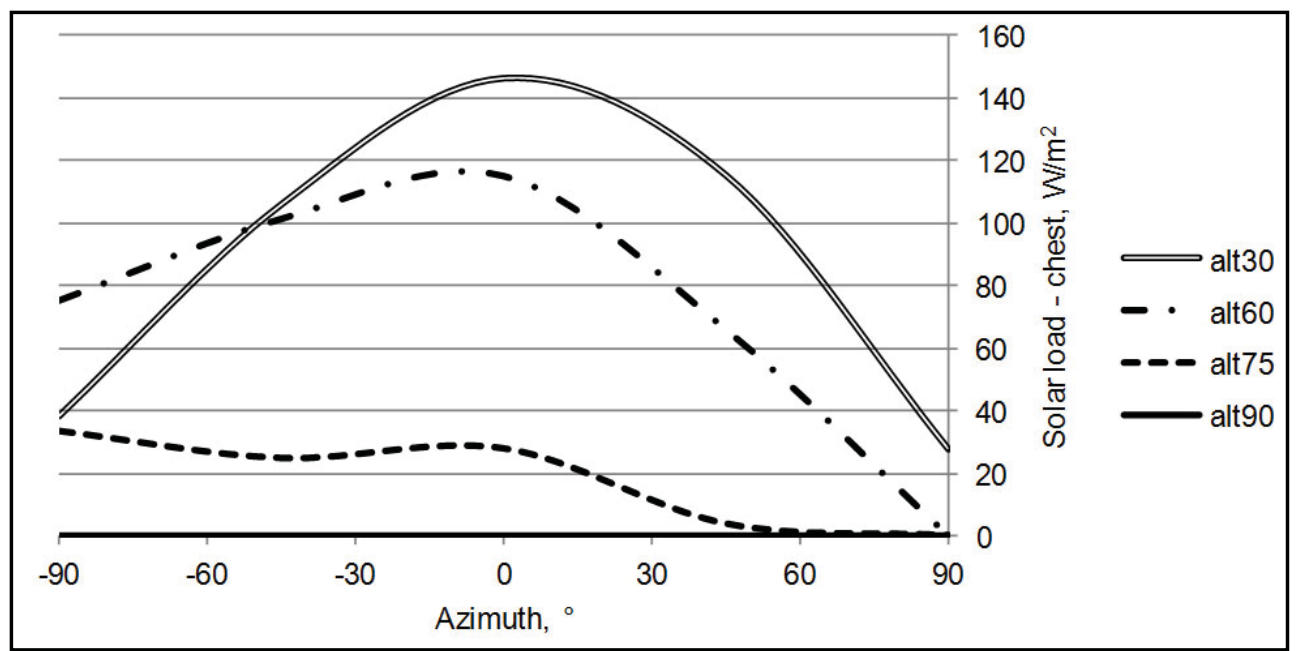

Figure 8: Values of the heat flux for the driver's chest in dependence of solar azimuth and altitude angles

Furthermore, the worst case regarding the asymmetry, evaluated using the difference of heat fluxes between the left and the right body segments, was the case when the sun is shining at the left side of the cabin (driver-side), at altitudes between $30^{\circ}$ and $60^{\circ}$ (Figure 8 ). In this case, the driver's body, and especially the face, are exposed to the strong asymmetric thermal condition. If this condition is prolonged, the asymmet- ric thermal load must be compensated by proper distribution of the air-conditioned air towards the areas exposed to the solar irradiation. 


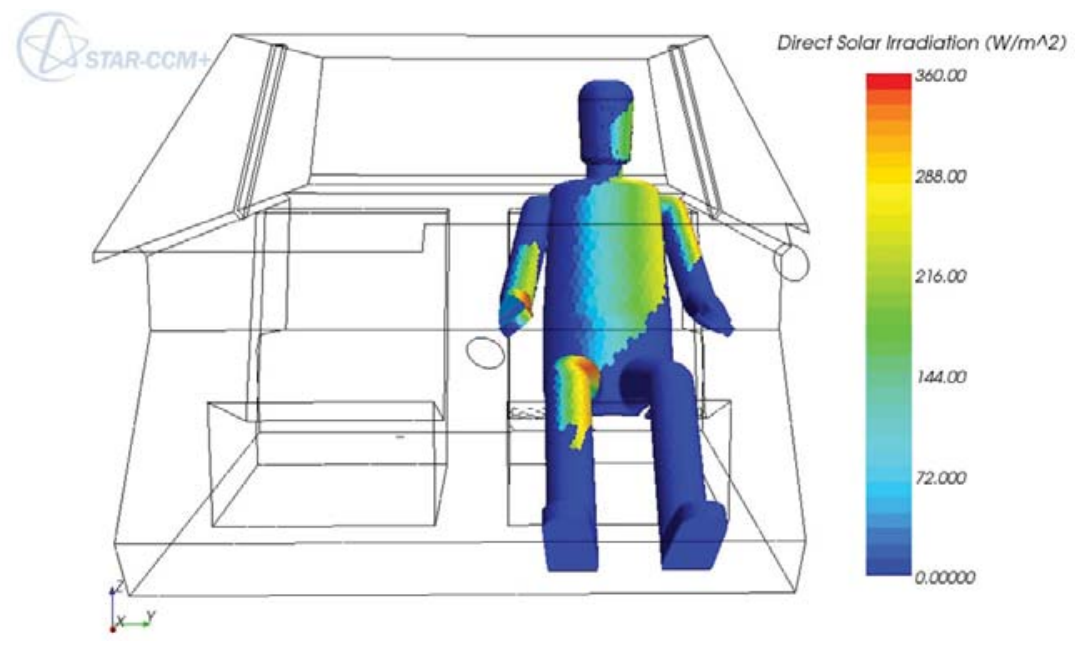

Figure 9: Distribution of the solar irradiation over the VTM's surface in the case with the high radiation asymmetry (solar altitude $45^{\circ}$, azimuth angle $-90^{\circ}$ )

\section{CONCLUSION}

The influence of the solar radiation direction and intensity on thermal flux on passenger vehicle driver's body surface was analysed using a virtual model of a vehicle cabin. The virtual experiments were carried out in CFD software STAR$\mathrm{CCM}+$, using Solar load model.

The results showed that the highest heat flux caused by solar irradiation could occur when the sun is shining in the front of the vehicle, under the same conditions as in standard ISO 145052: 2008 . The body segment with the highest heat flux is driver's chest, particularly when the sun is low in the sky. The unfavourable situation for the driver due to highly asymmetric condition is also when the sun is shining on the left side of the cabin, i.e. on the driver's side. The typical design of passenger car cabin and the position of the driver on the seat do not offer sufficient protection from the solar radiation. The reasons are the shape of car body determined by aerodynamic and visibility requirements as well as by ergonomic position of the driver.

In any case, the exposed body surfaces can be protected only by solar properties of glass, unless some kind of shading devices or direct body cooling by airflow from air-conditioner vents are used. In passenger vehicles the shading devices are limited only to the adjustable interior sun visors, capable to cover the upper part of the windshield or side window. Of course, the visors must not restrict the driver's normal field of vision. From that reason, paying attention to solar characteristics of glass (especially windshield) and to design of air distribution system in such way that air-conditioner vents can be directed to areas with the highest fluxes, are an efficient ways to reduce the driver's thermal load.

The advantages of the simulation method presented in this paper are the simplicity and independence from other modes of heat transfer. Although the gray thermal radiation model was used, the radiation can be modelled as spectrumdependent. In this case, for achieving accurate prediction of transmitted solar irradiation it is crucial to have spectral properties of glass. However, the numerical values obtained from the simulations should be considered for comparison purposes only, and validation of the numerical model must be done by physical experiment.

\section{ACKNOWLEDGMENT}

This research was done as a part of the project TR35041 - "Investigation of the safety of the vehicle as part of cybernetic system: Driver-Vehicle-Environment", which was supported by the Serbian Ministry of Education, Science and Technological Development. The authors wish to thank Dr Maša Bukurov for enabling the use of the CFD software STAR CCM+.

\section{REFERENCES}

1) Bohm, M., Holmer, I., Nilsson, H., Noren, O. (2002): Thermal Effects of Glazing in Driver's Cabs, JTI-rapport, JTI - Swedish Institute of Agricultural and Environmental Engineering, Uppsala, Sweden

2) Daanen, H.A.M., van de Vliert, E., Huang, $X$. (2005): Driving performance in cold, warm and thermoneutral environments, Applied 
Ergonomics, 34, pp. 597-602.

3) Dadour, I.R., Almanjahie, I., Fowkes, N.D., Keady, G., Vijayan, K. (2011): Temperature Variations in a Parked Vehicle, Forensic Science International, 207, pp. 205-211

4) Glišović, J. Demić, M., Miloradović, M. (2011): Review of Virtual Reality Applications for Reducing Time and Cost of Vehicle Development Cycle, Journal of Applied Engineering Science, 9(3), pp. 361-372

5) Han, T., Huang L. (2005): A Sensitivity Study of Occupant Thermal Comfort in a Cabin Using Virtual Thermal Comfort Engineering, 2005 SAE World Congress, SAE Tech. paper 2005-01-1509, Detroit, USA

6) Huizenga, C., Zhang, H., Mattelaer, P., Yu, T., Arens, E., Lyons, P. (2006): Window Performance for Human Thermal Comfort, Final Report to the National Fenestration Rating Council, Center for the Built Environment, University of California, Berkeley, USA

7) Incropera, F. P., DeWitt, D. P. (1981): Fundamentals of heat and mass transfer, New York: John Wiley \& Sons

8) Lee, W.J., Jang, E.Y., Lee, S.H., Ryou, H.S., Choi, S., Kim, Y. (2013): Influence of the spectral solar radiation on the air flow and temperature distributions in a passenger compartment, International Journal of Thermal Sciences, 75, pp. 36-44

9) Mitić, S., Rakićević, B., Stamenković, D., Popović, V. (2011): Advanced theoreticalexperimental method for optimization of dynamic behaviour of firefighting vehicle modular superstructures, Journal of Applied Engineering Science, 9(1), pp. 267-275

10) Ognjanović, M. (2008): Design in Mechanical Engineering - Multidisciplinary Approach, Istraživanja i projektovanja za privredu, 20, pp. $15-22$

11) Parsons, K. (2003) Human thermal environments: The effects of hot, moderate and cold environments on human health, comfort and performance, 2nd ed., London: Taylor \& Francis

12) Rugh, J. \& Farrington, R. (2008): Vehicle Ancillary Load Reduction Project Close-Out Report, Technical Report NREL/TP-540-42454, National Renewable Energy Laboratory, Golden, USA
13) Ružić, D., Bikić, S. (2013): An approach to the modeling of a virtual thermal manikin, Thermal Science, DOI:10.2298/TSCI130115115R, OnLine-First,

14) Ružić, D., Časnji, F. (2011): Agricultural tractor cab characteristics relevant for microclimatic conditions, Journal of Applied Engineering Science, 9(2), pp. 323-330

15) Ružić, D., Časnji, F. (2012) Thermal Interaction Between a Human Body and a Vehicle Cabin, Heat Transfer Phenomena and Applications, Rijeka: InTech, pp. 295-318

16) Ružić, D., Časnji F., Muzikravić V. (2007): Karakteristike stakla kao faktor od uticaja na mikroklimu u traktorskoj kabini, Traktori i pogonske mašine, 12(4), pp. 92-97

17) Sekulić, D., Dedović, V. (2011): Intercity bus users vibration comfort analysis through an oscillatory model with seven DOF using ADAMS/VIEW software, Journal of Applied Engineering Science, 9(3), pp. 401-410

18) http://re.jrc.ec.europa.eu/pvgis/apps3/pvest. php, accessed on January 10th, 2013

19) ISO 14505-2: 2008, Ergonomics of the thermal environment - Evaluation of the thermal environment in vehicles, Part 2: Determination of equivalent temperature

20) Saint-Gobain Sekurit, Glazing Manual, http:// www.saint-gobain-sekurit.com/en/downloads, retrieved on January 15th, 2013

21) STAR-CCM+, User Guide, CD-Adapco

Paper sent to revision: 24.10.2013.

Paper ready for publication: 05.12.2013. 